\title{
Basic Income, Eco-logical Ethics, and Interdependent Well-Being
}

Aiden Sisler (Technische Universität Berlin)

\section{Ecological Systems and Ethics of Interdependence}

We are born dependent upon a whole host of beings within sustaining environments and their affordances. Together these living planet conditions represent the eco-social determinants of health and well-being (Canadian Public Health Association (CPHA), 2015). As integral constituents of ecosystems, humans, other organisms, and resources interact to sustain conditions appropriate for life, including regulating climate and creating goods of intrinsic and extrinsic worth, through the exchange between living and non-living components. This deep interdependence typifies relations in ecological systems, of which we are all native, and into which we shall all pass away.

On a grand scale, multiple sources speak of the dynamic interplay of increasingly precarious working and living conditions, rampant levels of inequality alongside unparalleled environmental degradation and species loss, and the erosion of social security, well-being, and trust the world over (Atkinson 2015; Ceballos et al. 2015; Intergovernmental Panel on Climate Change (IPCC), 2014; Wilkinson \& Pickett 2014; World Economic Forum, 2013). Such impressions are reproduced at the personal level; participants in one recent cross-national study did not believe that their children would live lives better than theirs, and the majority expressed anxiety about society's basic fairness (Gerzema \& D'Antonio 2013). In touching on moral philosophical notions of what constitutes a good life, though, individuals converged on a decent job, meaningful connections, and a degree of security. Furthermore, individuals across the globe prefer universal values of harmony with humanity and nature, altruism, benevolence, and self-direction over that of violence, power, and coercion; and exhibit profound cross-group identification and solidarity (Lind 2002; McFarland 2011; Schwartz 2010).

These intersecting patterns of social justice movements and ecologically-minded transition have been summed-up as the shift from materialist to post-materialist societies ${ }^{1}$, though the pattern appears to be tapering off in some higher consumption regions. The CPHA warns, "ecological

${ }^{1}$ See Inglehart and Wetzel's World Values Survey research. 
decline is likely to widen inequalities in power, wealth, access to resources, and the related level of health" provided the "unremitting pressures of growing populations, growing per capita demand, more powerful and pervasive technology and the dominant paradigm of modernization" (2015, 13). What is more, the anthropogenically-grounded unequal impacts in human-environment relations-already present and highly unpredictablemay begin to spiral into stochastic crises without collective solutions.

Pairing these positions with the worldwide drive for progressive policy and a renewed democratisation of the political process, these observations highlight the value, desire, and struggle for lives lived peacefully, healthfully, and cooperatively with one another and the natural world. Ethics of responsibility, care, and justice feature amid the present debates for systemic reform which incorporate plurality and intersubjectivity into their discussions. Here, dialogue and co-constructive strategy recognizes the importance of considering relative conceptions and ethics of alterity, or that of what has been and continues to be considered "foreign," "wild," "other," with a feminine "mother nature" as a prime figure in the search for solutions.

Among the policies cited as most promising for attaining these ends, Basic Income has gained considerable attention since the original conceptions of its moral and ethical value in fair, just, and healthful societies of shared social, cultural, economic, and ecological accountability and abundance ${ }^{2}$. Much contemporary discussion around Basic Income tends to center either on its utopic ideals or application, including the logistics of transferring to various schemes $^{3}$ and the societal arrangements and cultural value shifts required for effective and non-harmful implementation. This paper takes up a confluence of issues from intersectional and ecological standpoints as a turn away from the "quick-fix" panacea-quality of much cross-partisan rhetoric on Basic Income. For these purposes, Table 1 outlines the stages of argumentation leveled at a Basic Income.

\section{Defining Basic Income}

A minimal definition of Basic Income, citizen's income or universal basic income incorporates the idea that every person or citizen, however defined, without means test or work requirement ${ }^{4}$, viz. irrespective of employment status or categorization, earnings, age, gender or other designations, should

2 See Philippe Van Parijs' extensive Basic Income literature, for example, The Universal Basic Income: Why Utopic Thinking Matters, and How Sociologists Can Contribute to It (2013).

${ }^{3}$ See, for instance, The Green Party of England and Wales (April, 2015) Consultation Paper, Basic Income: A Detailed Proposal.

${ }^{4}$ Basic Income Studies, http://www.degruyter.com/view/j/bis. 
receive a guaranteed unconditional minimum income from the state, as a monetary payment (i.e., weekly, monthly) with no or limited provisos as to how the amount, or the time of its payees, is spent ${ }^{5}$. Whilst some proponents emphasize subsidizing of "citizens" versus individuals as based upon their citizenship status (e.g., Fitzpatrick 1999), others highlight the universality of a Basic Income along human rights and dignified life claims, for instance. Ultimately, a utopic reading of Basic Income underscores humans' pursuit of freedom and equality in that, "it is about the power to decide what sort of life one wants to live" (Van Parijs 2013, 174). While our core requirements for ontogenesis are universal ${ }^{6}$ (e.g., safe living conditions, supply of and access to building blocks of life (clean drinking water and nutrients, social care and support), our individual choices and desires, to which we are all entitled, vary considerably, and a Basic Income arguably respects those predicates.

Abstract judicial human rights discourse both enables and constrains social justice, whereby notice can be diverted from the relationship of basic needs, rights, and variegations of humans' moral accounts in their diverse communities and ecologies (Landy 2013). While there is value in advancing and defending basic rights, however defined, the present piece narrows in on democratized participation and eco-social reflections. Following democratized deliberation, decision-making, and methodologies suitable to examining the diversity of life and complexity of networked environments, (e.g., integrative pluralism ${ }^{7}$, intersectionality-based policy analysis (IBPA)), the foci of collective solutions ought not to rest solely on minimal rights for some or the ethics and morals of sentient-beings' domination or marginalization. Rather, through examining intersecting processes by which power and inequality are produced, reproduced, and actively resisted, attention is drawn to both to positive potential for resilience, solidarity-building, and eco-social justice on a most complete, local through to international level (Dhamoon 2011).

Such inclusive methods open up to intersubjective discussion on already existing and developing ethical practices, moral theories, and social justice (Nussbaum, Sen), and their relation to theories of knowledge, power, and the production of "knowledge" and "ignorance," and so, creation of "underclass" and "disempowered" versus elite hegemonic groups (Steyn 2012).

Transformation can come about through looking at and critically investigating the root causes of social, economic, and environmental inequities, in which people are bound inextricably to a shared, pluralistic ecological existence.

Table 1Error! No sequence specified.: Tiered Opposition to Basic

\footnotetext{
${ }^{5}$ For example, requiring that a recipient spend at least a year living in the country of issuance.

${ }^{6}$ See Patricia Greenfield's theory of human development and social change which depicts the cultural variability of universal ontogenesis.

${ }^{7}$ See Sandra Mitchell's (2003) text, Biological Complexity and Integrative Pluralism. 153
} 
Income (BI) ${ }^{8}$

(not necessarily reflected in stage progression as points of deliberation are dynamically interlinked)

\begin{tabular}{|c|c|}
\hline Tier of Opposition & Oppositional Foundations \\
\hline Tier 1: BI could not be achieved. & $\begin{array}{l}\text { Empirical claims that a } \mathrm{BI} \text { is } \\
\text { impossible. }\end{array}$ \\
\hline $\begin{array}{l}\text { Tier 2: BI would be too difficult, } \\
\text { expensive, etc. to implement. }\end{array}$ & $\begin{array}{l}\text { Empirical claims that a BI is too } \\
\text { challenging or costly (e.g., } \\
\text { psychologically, } \\
\begin{array}{l}\text { socially, } \\
\text { economically, politically) to } \\
\text { implement. }\end{array}\end{array}$ \\
\hline $\begin{array}{l}\text { Tier 3: BI would be too negative } \\
\text { for society. }\end{array}$ & $\begin{array}{l}\text { Empirical claims about BI's } \\
\text { (adverse, iatrogenic) social } \\
\text { consequences such as its impact on } \\
\text { labour-leisure mix, "non- } \\
\text { productivity", conflicting social } \\
\text { outcomes between the choices around } \\
\text { additional work, evisceration of pre- } \\
\text { existing or hindering of potential } \\
\text { beneficial government services and } \\
\text { policies (e.g., solidarity-based systems } \\
\text { of social protection, social dividend } \\
\text { from a commons trust }{ }^{9} \text {, etc.). }\end{array}$ \\
\hline $\begin{array}{l}\text { Tier 4: BI lives would be worse } \\
\text { than non-BI lives. }\end{array}$ & $\begin{array}{l}\text { Normative / deontological claims } \\
\text { about the value of lives influenced by } \\
\text { BI compared to those not otherwise } \\
\text { affected by or granted BI. }\end{array}$ \\
\hline $\begin{array}{l}\text { Tier 5: i) Humankind considered } \\
\text { as a whole as well as along group } \\
\text { membership and identity lines (i.e., } \\
\text { women and men; age groupings; } \\
\text { ethnicities) and ii) the world as a } \\
\text { whole (i.e., global ecology), do not } \\
\text { stand to benefit from BI. }\end{array}$ & $\begin{array}{l}\text { Agent-relative grounds against } \\
\text { humans / governments / states, and } \\
\text { so on, directing BI, a distributive } \\
\text { socio-economic policy with } \\
\text { potentially significant ramifications. A } \\
\text { universally-allocated BI would not } \\
\text { necessarily benefit lives similarly } \\
\text { (socially, economically, etc.) through } \\
\text { freedom of opportunity and choice } \\
\text { which would be bad for humanity on } \\
\text { the whole. Assertions of BI's } \\
\text { maintenance and augmentation of the } \\
\text { gender division of labour features } \\
\text { among such arguments. }\end{array}$ \\
\hline
\end{tabular}

8 Based upon Bostrom's (2008) leveled presentation of posthuman argumentation.

${ }^{9}$ See Peter Barnes's (2014) With Liberty and Dividends for All for the middle-class targeted proposal of fair sharing of eco-social resources. 


\section{Levels of Objection}

Literature continues to mount on Levels $0-1$ (Table 1) which primarily focus on logistical concerns of Basic Income including: its feasibility, costing, and transition processes from present day systems, Basic Income's integration, whether children and pensioners receive additional income or variations of the Basic Income, and the necessity of imposing caps (e.g., limits to costs of rent, basic goods, services), in order for the possibility of success. ${ }^{10}$ These issues are crucial, but will not be taken up to restrict the scope to core macroand micro-level intersectional influences, spanning multiple levels. Obviously, this does not serve to neglect the importance of thinking on viability, costs, risks, side effects, and geo-political consequences.

In this vein, as Neil Thin writes, positive social theory and associated ethics in which a Basic Income must be situated and discussed, "insists on empathic effort to respect first-person subjectivity; and promotes holism and life course perspectives" (Thin 2014). Thus, pragmatic idealism proffers a complementary perspective to the pathological outlook thought to plague social and neoclassical economic theory which promotes zero-sum competition and self-interest over ethics of care $^{11}$ and the value of fairness and reciprocity 12 .

Accordingly, in pursuit of liberation, so as to foster parity, freedom, and well-being - the features of dignified lives in commune-a mix of policies and social structuration will form parts of an intersectional solution. No sole proposal, no matter how immaculately planned, can shoulder all the hopes of socio-cultural and economic reformation. In its place, it is essential to consider the nature and climate of collective responses and their multi-level social and ecological impacts.

A brief mention is due of one option for costing a Basic Income, a model floated by Rajesh Makwana of Share The World's Resources, which outlines a social dividend-funded Basic Income resulting from calculations around the value of common resources. However, in appraisal of the natural world by way of imposing numerically-reduced answers to complex moral and ethical questions of value can again be considered as perpetuating the external calculated focus on persons, living beings, and natural and created resources $^{13}$. The assertion that assigning a unitary quantitative symbol of value to everything ranging from intellectual property to water to shared childcare would be beneficial is challenging, if not misguided. Apart from the deontological principles of honouring the land and one another for their intrinsic beauty and worth, the long-term impacts of arguing for support of life as such,-for when we speak of environmental degradation, we speak of unquantifiable ecological destruction and death-due to particular cost-

10 See the Basic Income Earth Network (BIEN) for more on the variety of proposals.

11 See, for instance, Virginia Held's (2006) Ethics of Care: Personal, Political, and Global.

12 Based widely on Adam Smith's (1759) The Theory of Moral Sentiments.

${ }^{13}$ See Caring Economics: Conversations on Altruism and Compassion. Between Scientists, Economists, and the Dalai Lama (2015). 
benefit analyses, would fail to engender respect for natural capital ${ }^{14}$; it appeals to prescriptive, "tit-for-tat" moral ideologies.

Simply defending something based upon its Benthamic utility, collapsing intrinsic and extrinsic value from an alleged universal morally-neutral or agent-neutral position beyond being a top-down mechanistic incentivizing 15 schema, is reflective of a specific expansionist strand of economics-based thought and so-called "scientific" imperialism. While such a framework seems to acknowledge the economic value of diverse resources, monetizing the protection of the environment and framing Basic Income as an individual payout solution to what are systemic and globalized issues of inequality and ecosocial justice invites reductive utilitarian ethics at the cost of more important deontological moral positions. Particularly, various indigenous groups and non-dualist theological accounts, hold the land and human and interspecies relations as profane, transcending concerns for trade and in no way readily reducible to figures. The social dividend schema, like a misapplied Basic Income, leaves little room for these pluralities or for long-term commitment to universal principles of justness and care.

\section{Aversion to Basic Income and Its Democratic Deliberation: A Historical Context}

Historically, aspects of contemporary ethics and moral theory have ebbed and flowed from underpinning notions of Cartesian mind-body dualism to holistic unity of "becoming-with" and "being-in" the world ${ }^{16}$. In the modern era, an abstract disengaged homo economicus, not accountable to, responsible for, or dependent upon a natural state of ecological affairs-the model (hu-)man as rational, principally self-interested actor privileged by the likes of Mill, Smith, Aristotle, and most economic theory - continues to direct moral theory and ethics on an international scale to arguably devastating effect ${ }^{17}$. As an "agent", largely apart from nature and socially-unbound, homo economicus links up with some of the original foundations of the Enlightenment, in which "rationality" is considered as that which, along with contributing zero-sum "utility principles", governs human and socio-cultural thought and action, chiefly absent of a non-premeditated altruistic reciprocity ${ }^{18}$, kinship values ${ }^{19}$

\footnotetext{
14 See Charles Eisenstein's (2007) The Ascent of Humanity.

15 Priming individuals with extrinsic versus intrinsic values has been tied to decreased performance and well-being as well as increased ecological footprints (Sheldon, Nichols \& Kasser 2011).

${ }^{16}$ See for instance, Pre-Socratic philosophies to Heidegger's Dasein (Sein und Zeit) to Donna Haraway's (2008) When Species Meet.

17 See Daniel Cohen's (2014) Homo Economicus: The Last Modern Prophet.

18 See for instance, Peter Kropotkin's concept of mutual aid and Homo Reciprocans.

19 See accounts of diverse moral economies and decision-making (e.g., Marshall Sahlins, Thorsten Veblen, John Maynard Keynes).
} 
or ethics of care, kindness, and non-state-circumscribed socially-contracted sake $^{20}$.

This ego-centric view of morality and humankind comes up against, what Habermas envisions, a communicative rationality, giving voice to democratic ideals. In continuing the beneficial critical and critiquing elements of the Enlightenment period merged with naturally-arising principles of political deliberation in non-coercive, peaceable communities (i.e., equality, reciprocity, participatory inclusion, generalizability) ${ }^{21}$, allows for co-visioning of solutions and practices toward individual and collective well-being. Still, the complex negotiation around interdependence is nevertheless frequently conflated with negative socio-cultural beliefs of "dependence," that is, noneconomic capital possessing or "non-productive" labouring, and so nonagentic, non-"self-sufficient" 22 . The degrading of the value of diverse eco-social contributions against existing standards threatens these democratic political ideals and deliberative intentions, thereby suppressing interdependence's development of a moral framework and intersectional ethics, and spread of accordant practice and policy.

Interdependent relations encompass those in which members or participants are reliant or responsible to one another either on an emotional, economical, ecological, ethical and/or moral basis. Alternately, a dependent relation arises from an imbalance along one or more of these areas. This is not to say that interdependence is either autonomous or cooperative, it can be both: in allowing for autonomous participation through cooperation, as an example. Morally this is relevant in that a common dynamic between the individual's rights and the common or collective good need not be bipolar: interdependence allows space for the advancing of relatively more agentic goals (i.e., independence, freedom) in addition to social collective responsibility, a sense of social trust, and ethics of care, community, and so on (Bowles \& Gintis 2013). Recall these ideals represent the guiding tenets of a Universal Basic Income: attainment of equality and freedom (Van Parijs 2013) to which one could add ecosocial well-being and benevolence.

For the resolution of inevitable conflicts arising from the balance of different ethical and moral perspectives, a certain level of competence can be considered as requisite as such core issues are often incredibly complex and require multiple capabilities (e.g., socio-emotional, intellectual, political, moral (Lind's Moral Democratic Competence etc.). This framework populates some

${ }^{20}$ Bowles and Gintis's (2013 reprint) A Cooperative Species: Human Reciprocity and Its Evolution.

21 Including Jürgen Habermas and Amartya Sen's writings.

${ }^{22}$ For instance, the degradation of "social welfare", stereotypes of the "poverty trap", and other paternalistic and patronizing management of the poor or otherwise "socially-disadvantaged" (e.g., those without economic, political power, typically feminized workers or the unemployed, people with disabilities, ethnic minorities, etc.). The idea of a self-sufficient, free and unconstrained man is predicated on the lack of accordant rights to women (see Carole Pateman, Mary Astell) or the co-optation of their unpaid care and labour (see Women's Budget Group www.wbg.org.uk). 
of the social and ecological sciences focusing on the non-duality of mind-body or framing of competing versus reciprocal notions of agency and collectivity. Among the fields of ethics and moral philosophy, interdependent thinking is demonstrated in multi-perspectival feminist, cosmopolitan, and intersectional models ${ }^{23}$. The rising investigation into the large area of overlap in intersectionality, interdependence, and eco-social studies might contribute to ecologically-grounded Basic Income proposals, as in overarching feminist and trans-financial/economics cybernetic paradigms ${ }^{24}$. Nevertheless, while a truly representative and intersectional Basic Income should be drafted through public deliberation and self-determination, the principle of inclusion remains largely untouched without individuals' and communities' free and full participation. As it currently stands, particular voices are vastly overrepresented in the geo-political realm, where input and consent toward indigenous land rights, for instance, can be swayed through political lobbying or outright corruption, effectively precluding ethical responsibility toward groups and their living environments. At present, related initiatives for enshrining the right to healthy ecosystems are underway.

\section{Cultural Roots of Current Crises and Solutions}

Starting with modernity's prevailing ego-normative moral system up to current discussion of globalized development, linear and algorithmic-like systems of thought run in parallel and augment notions of "growth-oriented" production-striving work of the self-actualizing and moral self 25 . In this model, man comes to know himself and God through the fruits of his labour and the labour itself. Moreover, how this labour is carried out, whether it is the machinations of the mind or rendering of new technological supplementation of a mechanized, specialized, compartmentalized human, is reciprocally shaped by reinforcing metaphors (Lakoff), linguistic devices (Chomsky), and indeed, across the socio-cultural milieu of entire societies (Patricia Greenfield).

The new version of such a dominant worldview found in "Globalization" discourse impacts individuals differently based upon their group membership, groups' status, personal and relational identity and well-being, and arguably shapes entire societies (Wilkinson \& Pickett 2014). In this way, the spread of values related to "development," "production," "technological advance," and an overall entrepreneurial or growth orientation are frequently lauded while sustained contentment, prudence, harmonization with nature and the value of

23 See for instance, Martha Nussbaum and Amartya Sen's capabilities approach.

24 See the (2008) special issue of Basic Income focusing on gender and the P2P network exploring transfinancial modeling.

25 One of the most well-known being Max Weber's Protestant Ethic thesis. 
sociality are equated to "idleness," "non-productivity," and "inertness" 26. However, ecologists have long considered the notion of "sustained and sustainable growth or development" as primarily counterfactual and misappropriated. They talk instead of steady state or harmonized local economies based on ecological principles like permaculture where humans closely observe and work with, not against natural relationships ${ }^{27}$. This resembles the movement away from irrational, protracted, dull, and dangerous labour, much of which barely serves to fund the necessities of living and will become automated 28 , to the desire for more considered and experientially-based engagement with the world, one's community, and one's self.

While seeming to instil the naturalistic fallacy, as a biologically-based and dependent species, despite attempts to extricate ourselves from our biotic nature evident in many technocratic fantasies ${ }^{29}$, we must acknowledge our own health as ultimately inseparable from the global ecology. Our illusion of separateness has served empirical advance in the realm of the physical sciences for the task of accurately depicting physical principles, yet many of the interpretations of these findings as well as their misapplication to the natural of living beings and human relations is to commit false generalizations with great consequence. For this, advanced ethical and moral theory, a project of democratized, interconnected, and free people ought to work toward preserving and regenerating the life of the planet as a whole, toward a world we would wish to envision, devote resources to, and so, actualize.

The export and arguably forced neo-colonial imposition of homo economicus epistemological and ontological orientations is nothing new. Importantly, though, these views impose themselves onto specific cultures, societies, groups, and individuals to constrain and constrict free and fair participation and healthful social and ecological conditions. These "economicgrowth-at-all-costs" views give rise to and are further supported by discriminatory practices, institutionalized inequities and injustices at the systemic level, as well as individually aggregated stereotypes, themselves heuristic shorthands for quickly interpreting that which is complex and nuanced, and acts of prejudice and discrimination (Sidanius \& Pratto 2001). And so inequality and unjust distribution of wealth, bound up with social and ecological outcomes are perpetuated through their dynamic reinforcement across multiple contexts (Atkinson 2015). Ecological decline and collapse stemming from unchecked growth and extraction will further augment these inequalities, leaving present and future generations to scramble for survival.

${ }^{26}$ What Kurtis and Adams (2015) describe as, "Mainstream valorization of growthoriented relationality as a normative standard constitutes a case of neo-colonialism in psychological science with broad implications for human well-being".

27 E.g., Herman Daly and the Centre for Advancement of the Steady State Economy.

${ }^{28}$ See Frey and Osborne (2013) on the estimated $47 \%$ of US jobs at risk of automation.

${ }^{29}$ As in Ray Kurzweil's predictions' socio-economic clout, for instance. 
Unjust social policies beget inequality in a mutually reinforcing manner. It is thus imperative for localized and transnational drafting and implementation of a universally fair set of social policies as a feasible eco-socio-political basis for local and global well-being. Already, political groups have found support for Basic Income proposals (e.g., Scottish Common Weal, Green Party of England and Wales, Finland's Centre Party), and Basic Income has met international success from Namibia ${ }^{30}$ to Dauphin, Manitoba ${ }^{31}$ though ecological impacts have rarely been explicitly addressed. Moreover, programs of conditional and unconditional cash transfer initiatives ${ }^{32}$ have proven effective in economic growth indicators to girls' access to education in a number of regional contexts.

\section{Intersectionality and Alterity: Meeting Difference and Otherness with Compassion}

It remains to be seen who stands to particularly benefit from Basic Income. Applying an intersectional ecological lens which espouses plurality of models and perspectives, unlike the "shredding of human knowledge into disciplines" (Nsamenang 2006, 2), allows for better insight. Systemically measured, nonprivileged individuals 33 have been paid limited specific attention in Basic Income discussion with most debate preferring to speak of the citizenry as a whole. Basic Income discourse and dialogue interfaces on the intersecting of these various groups and identities (Mason 2010) of experience and advantage, and identifies a pro-active approach toward building eco-social resilience and community among individuals, for one another.

Ecological intersectional models hone in on "issues of social change and equality as shaped by intersectional dimensions... and aims to promote policies that address the social and structural roots of policy issues" (Hankivsky 2011, 5) as "inequalities are never the result of single, distinct factors. Rather, they are the outcome of intersections of different social locations, power relations and experiences" (ibid. 2). Likewise, power and privilege are also informed by looking at the overlapping social locations and experiences of different individuals across their contexts and lifespans.

Basic Income would arguably assist in stopping the cyclical spiraling toward the unjust allotment of wealth and breach of care-oriented ethics. It

\footnotetext{
30 Basic Income Grant Coalition - Namibia http://bignam.org/.

31 Guaranteed Minimum Income Experiment (1972) where overall community health significantly improved; the only groups to work less were mothers with newborns who spent more time with their infants and teenagers who spent more time on schoolwork and so exhibited higher graduation rates.

32 E.g., United Nations Girls' Education Initiative (April, 2015) Discussion Paper.

33 Generally considered as women; non-hetero-normative, securely employed nonprecariat (e.g., Giles \& Gintis 2014); non-elite university-educated; ethnic or religious minorities; those disabled by socio-political systems, those in the earliest and later stages of life; non-gender binary conforming; political radicals or dissidents, among others.
} 
indirectly addresses the moral and ethical implications of vast economic inequality and its accompanying social, cultural, health, and ecological inequalities by considering the absolute amounts and quality of core services, resources or capital needed for a comfortable, dignified existence ${ }^{34}$. Nonetheless, income limits are not always represented in Basic Income proposals in terms of parallel policy measures.

The form this allotment ought to take is debatable. Localized sharing economy practices such as time banks or Local Economic Trading Systems (LETS) might prove too challenging to transition to on an international level in the immediate short-term. Present and looming climate change impacts considered, collectively we do not have the ecological time scale demanded to universally grant Basic Income in alternate currency forms ${ }^{35}$. Nonetheless, an argument for long-term transition to a non-monetary constricted Basic 'Income' provision, lies in in a similar class of arguments toward re-imagining our relationship to money and the economy as one of necessity and shared social investment in our combined well-being, and not of competition, relative status, or other indicators of a competitive, asocial society (Eisenstein). When the mind has a drive to attain through competition or launch metaphorical "battle" against the "other" for quantifiable, measureable resources, there is little room for compassion and love, for self and other, the emotions Martha Nussbaum depicts in Political Emotions. If "Love is what gives respect for humanity its life," as Nussbaum writes, "making it more than a shell" than the preclusion of love by false division represents a key barrier to acknowledging the humanity and respect in and through our own interconnectedness to all.

When compassion for self and other are denied through desensitization to the plight of others and the moral intuitions and emotions within one's self, where feeling deeply is deemed "weak" whereas this level of exercising our most human qualities is regarded as "too dangerous" for survival purposes within a violent system. This type of psychic damage and social costs of denying the ability to feel for the other is evident in the Post-Traumatic Stress reactions of veterans, for instance. The collective psyche of societies occupied with money, consumption, status and domination precludes, contaminates and barricades the flow of harmonious efforts, creativity, self-direction, collective trust, and benevolence to other beings and the natural world. Paul Piff's work at the University of Cal Berkeley supports this display on an empirical experimental level as well as quantitative and qualitative analyses and results of market economy policy (Adair Turner, Atkinson) and lobbyist and non-democratic intrusion in governance (Gilens \& Page 2014).

The task here then is nothing less than a widespread cultural-socialpolitical re-shifting of values and norms. It demands an instituting of a prefigured ethical system of interdependent flourishing, in parallel to the concerted abolishing of the formerly described oppressive cultural roots of

\footnotetext{
${ }^{34}$ See the post-growth movement (e.g., Post-Growth Institute, postgrowth.org)

${ }^{35}$ However, see Faircoin (fair-coin.org), an experimental crypto-currency, for example 161
} 
present circumstance. The injustice of rife economic inequality and mounting socio-ecological threats, while mirroring much of what has ailed human freedom and well-being in the past, is the struggle of our times and for the generations to come. However, it need not be a destructive in the retributive sense. For in practicing the ethics of non-violence and compassionate existence, dismantling unequal power structures united with an emphasis on living better together would benefit a majority, if not all. Toward these ends, a processual, ecological systems-based, co-determined possibility of Basic Income can be made reality.

\section{Democratic Deliberation on Ecological Policy}

Participation in Basic Income drafting holds great consequence in the face of ever-greater impacts of free-market mentality in which individuals begin to view the world and their relationships and, indeed selfhood, through a zerosum, costs-based analysis. Whether reflected in an imaginary and actordependent trade-offs of the game theoretic framework spuriously applied writ large to the entirety of human relations, these perspectives are spreading across the globe. We do know that moral economies and frameworks vary across and within cultures yet we are at a loss as to definitive democratic deliberative processes toward valuing and working with difference, and learning to co-exist.

Like Habermas's progression from emphases on deliberative democratic process and the transition from authoritarian command and imperialism of the moral realm, inside modern cosmopolitan theory and praxis as well as from grass-roots engagement and action, there exists an the attempt to recognize, preserve and honour undeniable differences. These collective interdependent efforts speak to the continued and renewed commitment to creating shared spaces and practices of sitting with "the other" and listening to varied and interlinking perspectives. As tolerance of ambiguity is culturallyrelated and individually-variable, many are currently unable to be comfortable with difference, and tend toward increased incidence of stereotyping and prejudice for the need to label and assign value and categorize which often result in great social detriment.

Current work points toward the potential which lies within conflict, and rejects the idea that it necessarily requires immediate resolution or consensus ${ }^{36}$. Jung mentions the loss of the feminine in modern culture, in which solutions do not always necessitate immediate action, and difference and ambiguity are embraced and valued, not merely "tolerated" or "included." Such hastiness and moral hubris is readily apparent in the "white saviour" complex of a majority of transnational efforts titled under the guise of "development". This need for asserting one's will and authority on another fails to honour a plurality of perspectives and engage in a process of

${ }^{36}$ See L. A. Kaufmann (2015), The Theology of Consensus. 
discussion in which truly collective co-created and so, effective, reliable selfdetermined solutions may arise.

While it would be unwise to promote endless discussion and affirmation of total cultural relativism in pursuit of ethical and moral models of promoting eco-social well-being, it is crucial to recognize the inherent diversity and plurality of potential solutions and the individuals who must be accounted for in such processes (everyone, equally). As closely mapping the democratic models proposed by cosmopolitan theorists and on-the-ground activist movements (e.g., Adami 2013), an integrative pluralistic approach may prove valuable though again, ultimately much more complex and effortful at the outset. In terms of resilience, the balance between complexity and resilient responding and planning is but one of many benefits bestowing a practice which pays respect to a continuum of epistemology while never abdicating to reductionism nor chaos (Manson 2008). These principles are found within ecosystem intra- and interactions as so, must be honoured for sustainable well-being.

\section{Supportive Cultures of Ambiguity}

Certainly, undertaking transformation toward Basic Income requires a sense of humility, openness, and acceptance of the multi-perspectival nature of interdependence. For this, a sense of safety and security within oneself as well as the world and sociality at large is necessary for these two modes are mutually exclusive: one cannot concomitantly expand and retract. So mirrors contemporary thought from the merging of diverse spiritual, cultural practices and socio-political and economic efforts toward well-being. Self-compassion (Neff 2003) and self-awareness are intimately linked to "other"-compassion and a desire to learn of the "other." A strong version of this edict observable in diverse cultures and philosophies of Ancient Greece, Buddhism, Hinduism, Jewish Mysticism, to Australian indigenous epistemologies encourages thinking of one's self as an extension of all, seeing the ultimate connection to all things, of the relationship of immanence and transcendence, often through dialectical fashion.

In this way, interdependent inquiry of moral facts and values (which, contrary to Sam Harris's position ${ }^{37}$ and other dominant scientific reductionist notions of ethical naturalism), largely reject notions of science solely providing the means toward solutions to morality ${ }^{38}$. It could be similar to

37 See for instance, the position that values add up to empirical statements about "the flourishing of conscious creatures in a society." Harris argues that there are objective answers to moral questions, even if some are difficult or impossible to possess in practice.

38 Of course, science is critical for understanding aspects descriptively of human experience and ecological phenomena. It is something else to say that science/neuroscience thusly prescribes a moral nature for us to follow. This type of debate is reminiscent of Noam Chomsky's (1959) critique of B. F. Skinner's (1957) book, Verbal Behaviour. Chomsky underlines the rashness of a behaviorist and 163 
think of the desire to "be right," to provide answers, to solve or fix things, to treat and prescribe, characteristic of western worldviews. Likewise, it would be dehumanizing to suggest that seriously entertaining other cultures and epistemologies constitutes total cultural relativism or vitiates a global discourse around moral solutions to ecosocial well-being. By inhering within a shared collective culture of acceptance and difficult conversations around alterity, interdependence, and intersectionality, we might integrate what Jung termed our shadow, allowing for light to shine on and illuminate those parts overlooked and discarded, bringing them into the fold to reconcile, renew, and regenerate beyond relativistic stalemates. Such are the hopes of an ethics of an eco-logical approach to our collective variegated fate.

\section{The Socio-cultural Change - Policy Relationship: Considering Gender}

Fair and cooperative policies addressing media, education, labour, capital, environment, technology, and governance, to name but a few, must be harmonizing and synchronizing (Elgarte 2008). For this, there needs to be a cultural shift beyond restrictions of what constitutes "worthwhile" work, including the gendered division of labour. Katada (2012) combines aspects of two feminist theorists for bringing about the dissolution of gendered work. Firstly, "matters of level" apply in which an insufficient Basic Income will perpetuate inequality and divisions, forcing individuals, especially systemically-disenfranchised, into continued precarious, undesirable, or devalued work, whereas "a level sufficient for a modest and decent standard of life" (Pateman 2006) will allow for the rebalance of labour away from maleoriented working frameworks. Secondly, Basic Income might contribute to the goal of gender equality by seeking the socio-economic conditions necessary to bring about the gender divide's disbanding (Zelleke 2008). In this way, women and men might share equally in child and elder care and education, among other currently highly gendered fields, and their labour will be given the respect deserved. Such conditions concomitant with other policies and structural reorganization and revaluation would supplement the sociocultural mixture necessary for the successful adaptation and conservation of transformation.

Apart from supportive socio-ecological change and conditions, a poorly supported Basic Income could present a destructive force in the recasting or eliminating of social welfare and other needs-based necessities (i.e., child and health care, disability allowance) and core governmental services or else be significantly altered by the central organization in charge of its provision and terms (i.e., defining citizenship). Moreover, the shouldering of environmental

reductionist approach to depict language acquisition, development, and use, instead drawing attention to the incredibly complex and diverse phenomena in linguistics and human-environment relations. 
conservation and protection as well as other social welfare services could be written off as optional for the now provided for Basic Income recipients. A fair and equitable distribution of Basic Income demands an open, transparent, and democratic process of its planning and evaluation, and subsequent adjustment lest it be a constraint on freedom, respectful interdependence, and reciprocity.

In critique of an ego-oriented ontology which influences modern day economics, politics, and subsequent human relations-shaping policy, concepts of co-creation or sympoeisis where beings and materials are continually brought into existence, influencing one another (e.g., Haraway 2013) assist our understanding of why Basic Income could acknowledge this inescapable interdependence when applied within a supportive socio-cultural environment. When individuals are provided the core means for a free existence, security and safety characterize and guide their relations, rejecting the view of a dependent versus philanthropic class, for we are all connected and all dependent upon, and give to one another.

\section{Relationality, Alterity, And Interdependent Ethics: Transformational De-Centering}

Anya Topolski presents an alternative frame of relationality, which offers both an ethics and an epistemology based on a social-ontology inspired by Levinas and Arendt, as a concrete means to destabilise the casting of "us vs. them." Relationality, in its theoretical form, frames relations in terms of the interdependency and horizontality between co-constituting decentered subjects. Concretely, it asks us to consider our responsibility for otherswithin and without-when thinking, judging, and acting" (Topolski 2011, 2). This spirit lends itself to thinking of how Basic Income encourages applied ethics and guiding moral philosophies of responsibility toward ourselves and toward the unknowable "other" including nature.

In consideration of level five-type prepositions that Basic Income would benefit: 1) humankind as a whole as well as i) individual and ii) social relations and their potential and pre-existing groups plus 2) the global ecosystem, no simple deduction or set of predictions are fit to the task of explaining incredibly complex eco-social interdependence. Nonetheless, prior studies and theories seem to suggest at least two hypotheses: 1) that Basic Income outcomes will follow the contours of pre-existing socio-cultural arrangements, emphasizing, maintaining or re-directing these disparities or 2) that Basic Income will play a part of creating the conditions necessary for socio-cultural transformation.

This might then prove the crux of Basic Income arguments: an unconditional income provision would ultimately force the question of what type of future shall we either collectively co-envision and bring into being or have dictated for us or forced upon us by existing (inequitable unrepresentative) power structures. There is the need to exercise critical practices in evaluating the merits and bases for Basic Income implementation. 
The call for an "apolitical non-partisan solution" to society's and indeed the world's ills is premature, ahistorical, and naive, and could threaten to collapse difference or accentuate it through inequality as opposed to considering its intrinsic value to the diversity of life and resilience of ecosystems. Rather, in a best-case scenario, a Basic Income could play a role in new emerging deliberation and respect of difference in learning to peaceably co-exist, to live well individually and collectively, in pluralistic societies on a global eco-social foundation.

There are a number of serious factors to consider concerning the immediacy of pursuing ethical and moral foundations for eco-social wellbeing. As the Canadian Public Health Association's 2015 report, Global Change and Public Health: Addressing the Ecological Determinants of Health outlines, global ecological change is evident particularly in climate change, ecotoxicity, resource depletion, species extinction, oceanic degradation, and unprecedented challenges considered as incredibly challenging problems. Specifically, Levin et al. (2012) further delineate global climate change as characteristic of 'super wicked problems' (i.e., shortage of time, no one governing authority, solution seekers as problem causers, unwarranted disregarding of future). Much of these antecedents of global ecological change intimately connect to socio-cultural human forces like that of population explosion, urbanization, economic growth and development, technological shifts, and social value change (CPHA 2015). While such influences are outside much of the current models for conceptualizing and predicting human and ecosystem impact on the local and global level, they are essential in reenvisioning and stimulating the best way forward.

Basic Income can be taken as part of a seismic shift of dominant social values, spurring widespread social change toward harmonized and secure eco-social conditions. As a word of warning, it is at these crucial times of seemingly incomparable wealth and knowledge, and opportunity juxtaposed to widespread poverty, socio-cultural upheaval, and ailments of modernization that such reformatory ideas carry great weight. For professed well-intentioned aims are to be found even in political social systems which strip individuals of their basic rights to freedom of expression, safe, healthy environments, and collective and individual pursuit of happiness and justice. In this sense, a Basic Income as a democratic counter to power imbalance and state dependency (e.g., the crisis of immiseration, welfare's failings, discrimination and stigmatization) will need to directly face authoritarian sentiments and their moral systems, and the impending advance of renewed fanaticism in the face of group conflict and resource threat from such intertwined factors and myths surrounding globalization, economic crises, mass-scale financialization, and cultural clash.

On a concluding note, the CPHA outlines:

... critical to the success of these efforts is the understanding that the changes in the Earth's ecological systems are driven principally by our social and economic systems, and by the collective values and 
institutions that support them. As such, we see that the social and ecological determinants of health intertwine and interact, influencing each other and ultimately the health of people, communities and societies, along with the health of countless other species with whom we share the planet $(2015,1)$.

The pressing need for actualizing transformative eco-socially-based policy and practice is particularly evident when faced with impending mass extinction (Ceballos et al. 2015). It is in this spirit that an effective, interdependently and intersectionally aligned Basic Income might bring about the conditions toward a just, dignified, and healthful existence for all.

\section{References}

Adami, R. 2013. "Intersectional Dialogue: A Cosmopolitical Dialogue of Ethics." Cosmopolitan Civil Societies Journal 5(1): 45-62.

Atkinson, A.B. 2015. Inequality: What Can Be Done? Cambridge: Harvard University Press.

Canadian Public Health Association. 2015. CPHA Report: Global Change and Public Health: Addressing the Ecological Determinants of Health. Ottawa: CPHA.

Ceballos, G., Ehrlich, P., Barnosky, A., Garcia, A., Pringle, R., \& Palmer, T. 2015. "Accelerated Modern Human-Induced Species Losses: Entering the Sixth Mass Extinction." Science Advances 1(5), DOI: 10.1126/sciadv.1400253.

Dhamoon, R. 2011. "Considerations on Mainstreaming Intersectionality." Political Research Quarterly 64: 230-243.

Elgarte, J. 2008. "Basic Income and the Gendered Division of Labour." Basic Income Studies 3(1): 1-7.

Fitzpatrick, T. 1999. Freedom and Security. London: Palgrave.

Frey, C. B. \& Osborne, M. A. 2013. "The Future of Employment: How Susceptible Are Jobs to Computerisation?." OMS Working Paper. Retrieved on September, 7, 2013.

Gerzema, J. \& D'Antonio, M. 2013. The Athena Doctrine: How Women (and the Men Who Think Like Them) Will Rule the Future. Hoboken, NJ: John Wiley \& Sons.

Hankivsky, E. 2011. “Intersectionality 101." Burnaby: The Institute for Intersectionality Research \& Policy, Simon Fraser University.

Intergovernmental Panel on Climate Change 2014. Climate Change 2014: Impacts, Adaptation, and Vulnerability. Cambridge: Cambridge University Press. 
Katada, K. 2012, September. Basic Income and Feminism: In Terms of "the Gender Division of Labor." $14^{\text {th }}$ International Congress of the Basic Income Earth Network, Munich, Germany Proceedings: 14-16.

Landy, D. 2013. "Talking Human Rights: How Social Movement Activists Are Constructed and Constrained by Human Rights Discourse.” International Sociology 28(4): 409-428.

Levin, K., Cashore, B., Bernstein, S., \& Auld, G. 2012. "Overcoming the Tragedy of Super Wicked Problems: Constraining Our Future Selves to Ameliorate Global Climate Change." Policy Sciences 45(2): 123-152.

Lind, G. 2002. Ist Moral lehrbar? Ergebnisse der modernen moralpsychologischen Forschung. [Can Morality Be Taught? Research Findings from Modern Moral Psychology]. $2^{\text {nd }}$ edition. Berlin: LogosVerlag.

Manson, S. M. 2008. "Does Scale Exist? An Epistemological Scale Continuum for Complex Human-Environment Systems". Geoforum 39(2): 776788.

McFarland, S. 2011. "The Slow Creation of Humanity." Political Psych., 32(1): 1-20.

Mason, N.C. 2010. Leading at the Intersections: An Introduction to the Intersectional Approach Model for Policy \& Social Change. New York: Women of Colour Policy Network.

Neff, K. D. 2003. "The Development and Validation of a Scale to Measure SelfCompassion." Self and Identity 2(3): 223-250.

Nsamenang, A. B. 2006. "Human Ontogenesis: An Indigenous African View on Development and Intelligence." International Journal of Psychology 41(4): 293-297.

Pateman, C. 2006. "Democratizing Citizenship: Some Advantages of a Basic Income." In Ackerman, B., Alstott, A., \& Van Parijs, P. (Eds.), Redesigning Distribution. NY: Verso.

Schwartz, S. H. 2010. "Basic Values: How They Motivate and Inhibit Prosocial Behavior.” In Mikulincer, M. \& Shaver, P. (Eds.), Prosocial Motives, Emotions, and Behavior: The Better Angels of Our Nature. Washington: APA 14: 221-241.

Sidanius, J. \& Pratto, F. 2001. Social Dominance: An Intergroup Theory of Social Hierarchy and Oppression. Cambridge: Cambridge University Press.

Steyn, M. 2012. "The Ignorance Contract: Recollections of Apartheid Childhoods and the Construction of Epistemologies of Ignorance." Identities 19(1): 8-25.

Thin, N. 2014. "Positive Sociology and Appreciative Empathy: History and Prospects." Sociological Research Online 19(2).

Topolski, A. 2011. An Ethics of Relationality: Destabilising the Genocidal Frame of Us vs. Them. Preventing Genocide: Root Causes and Coping Strategies. University of Antwerp, Belgium, 24-25 November 2011.

WHO. (2011). Gender, Climate Change, and Health. Geneva: World Health Organisation. 
Wilkinson, R. \& Pickett, K. 2014. A Convenient Truth. London: Fabian Society. World Economic Forum. 2013. Outlook on the Global Agenda 2014. Davos, Switzerland: World Economic Forum.

Zelleke, A. 2008. "Institutionalizing the Universal Caretaker Through a Basic Income?." Basic Income Studies 3(1).

\title{
Aiden Sisler (Berlin)
}

Basic Income, Eco-logical Ethics, and Interdependent Well-Being

\begin{abstract}
A Basic Income (universal basic income or citizen's income) could contribute to the means for living a dignified ecologically- and socially-aligned life characterized by well-being, freedom, and equality. After laying out key definitions, I reflect on moral and ethical issues regarding Basic Income's implementation, backed by supportive theory and evidence. These arguments organise around interdependence in eco-social systems and core requirements of ontogenesis as well as the intersection and intertwining of socio-cultural, political, and economic factors, known as socio-ecological determinants of global health and well-being. Following that, I briefly make the case for why intersectional and intersubjective aspects should be closely held in contextualized view of Basic Income's democratised drafting and provision.
\end{abstract}

Keywords: Basic income, intersectionality, interdependent ethics, democratized lives, eco-social justice

Doi: 10.14746/eip.2014.2.11 